\title{
Negative Effects of Endoscopists' Fatigue on Colonoscopy Quality on 34,022 Screening Colonoscopies
}

\author{
Zhiyu Dong*, Junwen Wang*, Ying Chen, Huihui Sun, Bo Li, Qiongmei Zhang, Kejing Sun, Zhenxiang Wang, Xue Qian, \\ Tingting Zhan, Yuanxi Jiang, Shuchang Xu
}

Department of

Gastroenterology, Tongji

Hospital, Tongji University

School of Medicine,

Shanghai, China

Address for correspondence:

Dr. Shuchang Xu

Department of

Gastroenterology, Tongji

Hospital, Tongji University

School of Medicine,

Shanghai, China

xschang@163.com
Received: 22.04.2021

Accepted: 07.07.2021

* Equally contributed

\begin{abstract}
Background \& Aims: There is still considerable controversy surrounding the relationship between fatigue of endoscopists and the quality of colonoscopy. The aim of this study is to comprehensively explore the association between fatigue and adenoma detection rate (ADR) and cecal intubation rate (CIR).

Methods: The mixed effects logistic regression model was used to explore the relationship between fatiguerelated factors including procedure order, session of procedures and the day of week and ADR as well as CIR. Results: When controlling for confounders, the day of week (Monday as reference, Friday, $\mathrm{p}=0.022$; weekends, $\mathrm{p}=0.015)$ and session of procedures $(\mathrm{P}<0.001)$ were significantly associated with ADR while procedure order $(<5$ as reference, $6-10, p<0.001 ;>10, p=0.001)$ and session of procedures $(\mathrm{p}=0.004)$ were independent predictors for CIR. Additionally, there was a significant downward trend on ADR and CIR with the approaching of weekends $(p=0.005)$ and increasing procedure orders $(p<0.001)$, respectively. In the subgroup analysis stratified by gender, age and workload intensity, significant lower ADR was found in the afternoon in all subgroups (male, $\mathrm{p}<0.001$; female, $\mathrm{p}=0.005 ;<40$ years, $\mathrm{p}<0.001 ; \geq 40$ years, $\mathrm{p}=0.020$; intensity $<50$ per month, $\mathrm{p}=0.017$; intensity $\geq 50$ per month, $\mathrm{p}<0.001$ ) but the downward trend on ADR as the week progressed was only found in endoscopists with male gender $(\mathrm{p}=0.011)$, age $<40(\mathrm{p}=0.027)$ and high workload intensity $(\mathrm{p}=0.003)$. Moreover, a significant downward trend on CIR as the procedure order increased was found in all subgroups except endoscopists with age $\geq 40$ (male, $\mathrm{p}=0.005$; female, $\mathrm{p}<0.001$; $<40$ years, $\mathrm{p}<0.001$; intensity $<50$ per month, $\mathrm{p}=0.001$; intensity $\geq 50$ per month, $\mathrm{p}<0.001$ ).

Conclusions: Colonoscopies in the afternoon will affect ADR negatively while increasing procedure order will cause a lower CIR. Importantly, the significant negative influence of Friday and weekends on ADR was first discovered in this study. Moreover, endoscopists with female gender and advanced age ( $\geq 40)$ but not high workload intensity showed superiority in resistance of fatigue caused by the end of the week and increasing daily procedures.
\end{abstract}

Key words: fatigue - screening colonoscopy - colonoscopy quality - adenoma detection rate - cecal intubation rate.

Abbreviations: ADR: adenoma detection rate; BBPS: Boston bowel preparation scale; CIR: cecal intubation rate; $\mathrm{CRC}$ : colorectal cancer.

\section{INTRODUCTION}

Colorectal cancer (CRC) is the third most common cancer worldwide and ranks fourth as a cause of cancer death [1]. Although colonoscopy is deemed to be the gold standard screening test of CRC [2], about a quarter of colorectal neoplasms are reported to be missed [3] and undetected lesions are responsible for $50 \%$ to $60 \%$ interval cancer [4]. Given that the practice of colonoscopy is operator-dependent, endoscopists' personal factors are of great concern. Fatigue due to long work hour and heavy workload is strongly proved to be harmful to the physician's cognitive functioning and eventually leads to increased medical error [5-9]. Thus, it's easy to hypothesize that fatigue accumulated during repetitive and sequential work of endoscopists would affect the performance of colonoscopy.

Adenoma detection rate (ADR) and cecal intubation rate (CIR) are considered as robust quality benchmarks for screening-related colonoscopy [10]. Many studies have used $\mathrm{ADR}$ or CIR to observe the effect of fatigue on colonoscopy 
quality, but they define fatigue in different ways. Early studies have focused on the influence of timing on ADR but the results have varied [11-13]. On the other hand, a few articles have reported the changes of ADR or CIR in pace with the number or intensity of colonoscopy procedures [14-17], which seem to be more intuitive indicators to reflect the repetitive and prolonged nature of fatigue. As a consequence of diverse observation targets and inconsistent analysis methods shown in previous research, it has not been conclusively concluded whether the endoscopists' workload has reached the point of fatigue causing decreased ADR or CIR.

The aim of our study was to determine the association between fatigue and quality of colonoscopy. To study fatigue more comprehensively, we discussed the influence of session of procedures, increasing number of procedure order and the day of the week on ADR or CIR respectively. In addition, we attempted to figure out whether endoscopists' personal characteristics such as gender, age and overall workload would affect their resistance to fatigue.

\section{METHODS}

All colonoscopy data and histological information were obtained from endoscopic procedure database and pathological database respectively at Tongji Hospital in Shanghai, China between 1st January, 2012 and 30th June, 2019. This was a retrospective study and was approved by the Ethics Committee of Tongji Hospital (K-W-2020-012). All basic information and medical records including patient age and gender, the use of sedation, bowel preparation, endoscopic manifestation and time of procedures were included in our study. The endoscopists' factors such as age and gender were also recorded.

Boston bowel preparation scale (BBPS) was used to evaluate the bowel preparation quality of each segment of colon (right, transverse and left colon). A good bowel preparation was defined as a total BBPS $\geq 6$ with a partial BBPS $\geq 2$ in each segment.

Among all the endoscopists in our endoscopy center, 5 experienced endoscopists were qualified to arrange their working time and working hours on performing screening colonoscopies because they had to spare more time on therapeutic gastrointestinal endoscopy and other administrative work. In addition, some of them would have liked to arrange patients with a high risk to a later order so as to have more time to inspect. All of these made their work modes different from those of other endoscopists and might have had an impact on fatigue of them and lead to bias. Thus, we excluded these 5 experienced endoscopists and their colonoscopy data from our study.

\section{Primary outcome measures}

The primary outcome measures were ADR and CIR. The ADR was defined as the percentage of colonoscopies with at least one adenoma identified. The CIR was defined as defined as the proportion of procedures reaching and visualizing the whole cecum or terminal ileum.

\section{Statistical analysis}

We sorted the colonoscopies in ascending temporal order for all endoscopists enrolled and assigned a procedure order to each case. The procedure order reflected the rank of each colonoscopy for each endoscopist in a day. The morning and afternoon session were scheduled from 8 a.m. to 1 p.m. and 1 p.m. to 5 p.m. respectively.

According to previous studies, we considered procedure order [14-17], session of procedures [11-13] and day of the week [18] as fatigue-related factors. The student t-test, one-way ANOVA and chi-square test were used to compare the basic information, medical records and outcome measures between subgroups stratified by fatigue-related factors.

A mixed effects logistic regression model was used to explore the relationship between fatigue and primary outcome measures when adjusting for other potential confounders. To accommodate the hierarchical nature of the data, the endoscopists were used as random intercept terms to accommodate the clustering effects. The endoscopist factors including age, gender and workload intensity (number of procedures per month) and patient factors including age, gender, bowel preparation and sedation for procedures were considered as fixed effects and confounders. The workload intensity of each endoscopist was calculated by dividing the total number of procedures by the period of continuous performing colonoscopy. Considering the breaks of performing colonoscopy due to an endoscopist's reassignment or other personal reasons, any periods of 30 days or more when no data were recorded in the database was subtracted in the period we calculated.

All reported $p$ values were two-sided with $p<0.05$ defined as statistical significance. All analyses were performed using $\mathrm{R}$ ( $\mathrm{R}$ foundation for Statistical Computing, Vienna, Austria).

\section{RESULTS}

A total of 34,022 screening colonoscopy data were obtained from our database and used for further analysis. The basic information and ADR as well as CIR stratified by different fatigue-related factors for each endoscopist were presented in Table S1. There were significant differences in patient age $(p<0.001)$, patient gender $(p=0.002)$, bowel preparation $(p=0.023)$, sedation for procedures $(p=0.049)$ and adenoma detection $(p=0.005)$ between subgroups stratified by procedure order (Table I). The ADR was significantly lower in colonoscopies with procedure order 6-10 compared with colonoscopies with procedure order 1-5 (group 1-5 vs group $6-10,23.0 \%$ vs $21.5 \%$, adjusted $\mathrm{p}=0.014$ ). However, there was no significant difference in cecal intubation between subgroups $(\mathrm{p}=0.290)$.

As for subgroups stratified by session of procedures (Table II), there were significant differences in patient age $(\mathrm{p}<0.001)$, patient gender $(p=0.015)$, sedation for procedures $(p<0.001)$, cecal intubation $(\mathrm{p}<0.001)$ and adenoma detection $(\mathrm{p}<0.001)$ between different subgroups. The higher CIR and lower ADR were found in colonoscopies in the afternoon compared with colonoscopies in the morning (morning vs afternoon, CIR, 95.6\% vs $96.5 \%, \mathrm{p}<0.001$; ADR, $26.2 \%$ vs $21.1 \%$, $\mathrm{p}<0.001$ ).

Fig. 1 illustrated the trend of ADR and CIR hour-by-hour. CIR declined gradually from 8:00-12:00, recovered after a lunch break at noon and repeated the downward trend again from 13:00-17:00 while the same trend did not occur in ADR. 
Table I. Difference on characteristic of patients and colonoscopy quality between colonoscopies with different daily ranking

\begin{tabular}{lcccc}
\hline & \multicolumn{3}{c}{ Daily procedures } & \multirow{2}{*}{$\mathrm{p}$} \\
\cline { 2 - 4 } & $1-5$ & $6-10$ & $>10$ & \\
\hline Total & 24,200 & 8,012 & 1,810 & \\
Age, mean (SD) & $47.5(14.7)$ & $44.9(14.9)$ & $45.1(14.6)$ & $<0.001$ \\
Gender, n (\%) & & & & \\
$\quad$ Male & $12,199(50.4)$ & $4,163(52.0)$ & $977(54.0)$ & \\
$\quad$ Female & $12,001(49.6)$ & $3,849(48.0)$ & $833(46.0)$ & 0.002 \\
Bowel preparation, n (\%) & & & & \\
$\quad$ Good & $23,162(95.7)$ & $7,644(95.4)$ & $1,753(96.9)$ & \\
$\quad$ Not good & $1,038(4.3)$ & $368(4.6)$ & $57(3.1)$ & 0.023 \\
Sedation, n (\%) & & & & \\
$\quad$ No sedation & $2,590(10.7)$ & $781(9.7 \%)$ & $195(10.8)$ & \\
$\quad$ Sedation & $21,610(89.3)$ & $7,231(90.3)$ & $1,615(89.2)$ & 0.049 \\
Cecal intubation, $\mathrm{n}(\%)$ & $23,315(96.3)$ & $7,689(96.0)$ & $1,739(96.1)$ & 0.290 \\
Adenoma detection, $\mathrm{n}(\%)$ & $5,571(23.0)$ & $1,721(21.5)$ & $382(21.1)$ & 0.005 \\
\hline
\end{tabular}

Table II. Difference on characteristic of patients and colonoscopy quality between colonoscopies in the morning and afternoon

\begin{tabular}{lccc}
\hline & \multicolumn{2}{c}{ Time of procedures } & \multirow{2}{*}{$\mathrm{p}$} \\
\cline { 2 - 3 } & Morning & Afternoon & \\
Total & 9,854 & 24,168 & \\
Age, mean (SD) & $49.6(14.6)$ & $45.6(14.7)$ & $<0.001$ \\
Gender, n (\%) & & & \multirow{2}{*}{0.015} \\
$\quad$ Male & $4,920(49.9)$ & $12,419(51.4)$ & \\
$\quad$ Female & $4,934(50.1)$ & $11,749(48.6)$ & \\
Bowel preparation, $\mathrm{n}(\%)$ & & & \\
$\quad$ Good & $9,431(95.7)$ & $23,128(95.7)$ & 0.989 \\
$\quad$ Not good & $423(4.3)$ & $1,040(4.3)$ & \\
Sedation (N(\%)) & & & $<0.001$ \\
$\quad$ No sedation & $488(5.0)$ & $3,078(12.7)$ & \\
$\quad$ Sedation & $9,366(95.0)$ & $21,090(87.3)$ & \\
Cecal intubation $(\mathrm{N}(\%))$ & $9,423(95.6)$ & $23,320(96.5)$ & $<0.001$ \\
Adenoma detection $(\mathrm{N}(\%))$ & $2,580(26.2)$ & $5,094(21.1)$ & $<0.001$ \\
\hline
\end{tabular}

Mixed effects logistic regression analysis of relationship between fatigue and adenoma detection

The results from mixed effects logistic regression model of factors associated with adenoma detection are shown in Table III. The workload intensity of endoscopists, patient age, patient gender, bowel preparation and sedation for procedures were independent predictors for adenoma detection.

As for fatigue-related factors, session of procedure and the day of the week but not procedure order were significantly associated with ADR when adjusting for other confounders. Among these factors, ADR was significantly lower in colonoscopies in the afternoon (OR=0.84, 95\%CI: 0.79-0.90, $\mathrm{p}<0.001)$ and colonoscopies on Friday $(\mathrm{OR}=0.89,95 \% \mathrm{CI}: 0.81$ $0.98, \mathrm{p}=0.022)$ and weekends $(\mathrm{OR}=0.78,95 \% \mathrm{CI}: 0.63-0.95$, $\mathrm{p}=0.015)$ compared with colonoscopies on Monday.

Then, we converted the factors, procedure order and day of the week, into ordinal variables and explored the trend between

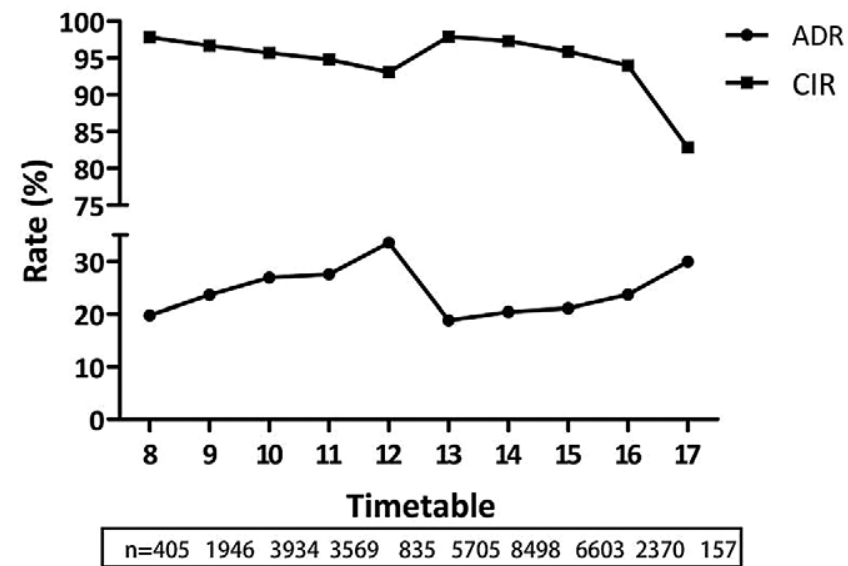

Fig. 1. Trend of adenoma detection rate and cecal intubation rate hourby-hour. ADR, adenoma detection rate, CIR, cecal intubation rate.

these two fatigue-related factors and ADR when adjusting for other factors. The trend analysis showed that there was a significant downward trend on ADR with the approaching of weekends (OR=0.97, 95\%CI:0.95-0.99, $\mathrm{p}=0.005)$.

In the subgroup analysis stratified by gender, age and workload intensity of endoscopists (Table IV), significant lower $\mathrm{ADR}$ was found in colonoscopies in the afternoon compared to colonoscopies in the morning in all of these subgroups. However, the significant downward trend on ADR with the approaching of weekends obtained from all colonoscopy data was only found in colonoscopies performed by endoscopists with male gender $(p=0.011)$, age $<40$ years old $(p=0.027)$ and high workload intensity $(\mathrm{p}=0.003)$.

Mixed effects logistic regression analysis of relationship between fatigue and cecal intubation

The results from the mixed effects logistic regression model of factors associated with cecal intubation were shown in Table III. The workload intensity of endoscopists, endoscopist age, patient age, patient gender and sedation for procedures were significantly associated with cecal intubation. 
Table III. Mixed effects logistic regression model including procedure order as one of fatigue-related factors

\begin{tabular}{|c|c|c|c|c|c|c|}
\hline & \multicolumn{3}{|c|}{ Adenoma detecion } & \multicolumn{3}{|c|}{ Cecal intubation } \\
\hline & N (\%) & OR (95\%CI) & $\mathrm{p}$ & N (\%) & OR (95\%CI) & $\mathrm{p}$ \\
\hline \multicolumn{7}{|c|}{ Endoscopist factor } \\
\hline \multicolumn{7}{|l|}{ Daily procedure } \\
\hline $1-5$ & $5,571(23.0)$ & Reference & & $23,315(96.3)$ & Reference & \\
\hline 6-10 & $1,721(21.5)$ & $1.01(0.94-1.08)$ & 0.779 & $7,689(96.0)$ & $0.71(0.61-0.82)$ & $<0.001$ \\
\hline$>10$ & $382(21.1)$ & $0.95(0.83-1.08)$ & 0.414 & $1,739(96.1)$ & $0.64(0.49-0.84)$ & 0.001 \\
\hline Trend $^{*}$ & & $0.99(0.94-1.04)$ & 0.702 & & $0.76(0.68-0.85)$ & $<0.001$ \\
\hline \multicolumn{7}{|c|}{ Session of procedure } \\
\hline Morning & $2,580(26.2)$ & Reference & & $9,423(95.6)$ & Reference & \\
\hline Afternoon & $5,094(21.1)$ & $0.84(0.79-0.90)$ & $<0.001$ & $23,320(96.5)$ & $1.22(1.07-1.40)$ & 0.004 \\
\hline \multicolumn{7}{|l|}{ Day of the week } \\
\hline Monday & $1,368(23.2)$ & Reference & & $5,676(96.2)$ & Reference & \\
\hline Tuesday & $1,675(22.3)$ & $0.96(0.88-1.05)$ & 0.431 & $7,206(95.9)$ & $1.03(0.85-1.24)$ & 0.772 \\
\hline Wednesday & $1,703(22.2)$ & $0.92(0.84-1.01)$ & 0.075 & 7,409 (96.6) & $1.19(0.98-1.45)$ & 0.074 \\
\hline Thursday & $1,496(22.0)$ & $0.93(0.85-1.02)$ & 0.139 & $6,548(96.2)$ & $1.10(0.91-1.33)$ & 0.331 \\
\hline Friday & $1,291(23.7)$ & $0.89(0.81-0.98)$ & 0.022 & $5,237(96.2)$ & $1.07(0.87-1.31)$ & 0.530 \\
\hline Weekends & $141(20.5)$ & $0.78(0.63-0.95)$ & 0.015 & $667(96.8)$ & $1.20(0.76-1.88)$ & 0.434 \\
\hline Trend $^{*}$ & - & $0.97(0.95-0.99)$ & 0.005 & - & $1.02(0.98-1.07)$ & 0.311 \\
\hline \multicolumn{7}{|c|}{ Adjusted intensity } \\
\hline$<50$ & $4,257(22.0)$ & Reference & & $18,590(95.9)$ & Reference & \\
\hline$\geq 50$ & $3,417(23.4)$ & $1.27(1.00-1.61)$ & 0.046 & $14,153(96.8)$ & $1.41(1.11-1.80)$ & 0.005 \\
\hline \multicolumn{7}{|l|}{ Gender } \\
\hline Male & $3,925(21.7)$ & Reference & & $17,462(96.4)$ & Reference & \\
\hline Female & $3,749(23.6)$ & $0.87(0.71-1.07)$ & 0.191 & $1,5281(96.1)$ & $0.89(0.71-1.11)$ & 0.314 \\
\hline \multicolumn{7}{|l|}{ Age } \\
\hline$<40$ & $6,988(22.3)$ & Reference & & $30,083(96.1)$ & Reference & \\
\hline$\geq 40$ & $686(25.1)$ & $1.23(1.12-1.34)$ & $<0.001$ & $2,660(97.3)$ & $1.16(0.98-1.37)$ & 0.090 \\
\hline \multicolumn{7}{|l|}{ Patient factor } \\
\hline \multicolumn{7}{|l|}{ Age } \\
\hline$<30$ & $82(3.9)$ & Reference & & $2,070(98.4)$ & Reference & \\
\hline $30-49$ & $1,000(11.7)$ & $3.23(2.56-4.07)$ & $<0.001$ & $8,386(98.3)$ & $0.86(0.59-1.26)$ & 0.432 \\
\hline $50-69$ & $5,116(26.8)$ & $9.59(7.67-11.99)$ & $<0.001$ & $18,387(96.3)$ & $0.39(0.27-0.55)$ & $<0.001$ \\
\hline$\geq 70$ & $1,476(34.3)$ & $\begin{array}{c}13.46(10.69- \\
16.96)\end{array}$ & $<0.001$ & $3,900(90.7)$ & $0.15(0.10-0.21)$ & $<0.001$ \\
\hline \multicolumn{7}{|l|}{ Gender } \\
\hline Male & $4,659(26.9)$ & Reference & & $16,589(95.7)$ & Reference & \\
\hline Female & $3,015(18.1)$ & $0.53(0.50-0.56)$ & $<0.001$ & $16,154(96.8)$ & $1.43(1.28-1.61)$ & $<0.001$ \\
\hline \multicolumn{7}{|c|}{ Bowel preparation } \\
\hline Good & $7,356(22.6)$ & Reference & & $31,336(96.2)$ & Reference & \\
\hline Not good & $318(21.7)$ & $0.79(0.69-0.91)$ & 0.001 & 1,407 (96.2) & $1.10(0.83-1.46)$ & 0.517 \\
\hline \multicolumn{7}{|l|}{ Sedation } \\
\hline No sedation & $661(18.5)$ & Reference & & 3,367 (94.4) & Reference & \\
\hline Sedation & $7,013(23.0)$ & $1.33(1.21-1.46)$ & $<0.001$ & $29,376(96.5)$ & $1.68(1.43-1.97)$ & $<0.001$ \\
\hline Random effect & & SD & & & SD & \\
\hline Endoscopists & & 0.18 & & & 0.17 & \\
\hline
\end{tabular}

As for fatigue-related factors, procedure order and session of procedures were significantly associated with cecal intubation when adjusting for other confounders. Among these factors, The CIR was significantly lower in colonoscopies with procedure order $6-10(\mathrm{OR}=0.71,95 \% \mathrm{CI}$ : $0.61-0.82$, $\mathrm{p}<0.001)$ and procedure order $>10(\mathrm{OR}=0.64,95 \% \mathrm{CI}$ : 0.50 - 
Table IV. Relationship between fatigue-related factors and adenoma detection rate stratified by different endoscopists ' factors

\begin{tabular}{|c|c|c|c|c|c|c|}
\hline & Male & Female & $<40$ years & $\geq 40$ years & $\begin{array}{c}\text { Intensity } \\
(<50 \text { per month })\end{array}$ & $\begin{array}{c}\text { Intensity } \\
(\geq 50 \text { per month })\end{array}$ \\
\hline \multicolumn{7}{|c|}{ Procedure order } \\
\hline $1-5$ & Reference & Reference & Reference & Reference & Reference & Reference \\
\hline $6-10$ & 1.07 (0.97-1.17) & $0.94(0.85-1.04)$ & $1.07(0.98-1.17)$ & $0.90(0.80-1.01)$ & $1.02(0.93-1.13)$ & $1.02(0.92-1.12)$ \\
\hline$>10$ & $0.98(0.81-1.18)$ & $0.91(0.76-1.09)$ & $0.98(0.84-1.15)$ & $0.87(0.69-1.10)$ & $1.00(0.67-1.50)$ & $0.97(0.84-1.12)$ \\
\hline $\mathrm{p}$ for trend $\mathrm{d}^{*}$ & 0.472 & 0.183 & 0.439 & 0.066 & 0.708 & 0.834 \\
\hline \multicolumn{7}{|c|}{ Session of procedure } \\
\hline Morning & Reference & Reference & Reference & Reference & Reference & Reference \\
\hline Afternoon & $0.82(0.75-0.90)$ & $0.87(0.79-0.96)$ & $0.81(0.75-0.89)$ & $0.88(0.80-0.98)$ & $0.91(0.83-0.98)$ & $0.74(0.67-0.82)$ \\
\hline $\mathrm{p}$ for trend ${ }^{*}$ & $<0.001$ & 0.005 & $<0.001$ & 0.020 & 0.017 & $<0.001$ \\
\hline \multicolumn{7}{|l|}{ Day of week } \\
\hline Monday & Reference & Reference & Reference & Reference & Reference & Reference \\
\hline Tuesday & $1.03(0.91-1.16)$ & $0.90(0.79-1.03)$ & $0.97(0.87-1.08)$ & $0.96(0.82-1.13)$ & $0.98(0.87-1.12)$ & $0.96(0.85-1.09)$ \\
\hline Wednesday & $0.94(0.83-1.06)$ & $0.89(0.77-1.03)$ & $0.91(0.82-1.02)$ & $0.95(0.81-1.11)$ & $0.99(0.87-1.12)$ & $0.84(0.73-0.96)$ \\
\hline Thursday & $0.94(0.83-1.05)$ & $0.92(0.79-1.07)$ & $0.94(0.84-1.05)$ & $0.94(0.81-1.10)$ & $0.97(0.85-1.10)$ & $0.91(0.80-1.03)$ \\
\hline Friday & $0.89(0.78-1.01)$ & $0.90(0.77-1.05)$ & $0.89(0.79-1.00)$ & $0.93(0.78-1.10)$ & $0.93(0.81-1.06)$ & $0.87(0.76-1.00)$ \\
\hline Weekends & $0.81(0.62-1.06)$ & $0.74(0.54-1.01)$ & $0.82(0.63-1.05)$ & $0.72(0.51-1.02)$ & $0.93(0.69-1.24)$ & $0.64(0.48-0.85)$ \\
\hline $\mathrm{p}$ for trend $\mathrm{d}^{*}$ & 0.011 & 0.207 & 0.027 & 0.180 & 0.251 & 0.003 \\
\hline
\end{tabular}

Analyses were adjusted for fatigue, endoscopist and patient related factor when they were not the strata variables. Trend ${ }^{\star}$, the variable was converted into ordinal variable and included into model.

$0.85, \mathrm{p}=0.001)$ compared with colonoscopies with procedure order 1-5 and significantly higher in colonoscopies in the afternoon (OR=1.22, 95\%CI: 1.07-1.40, $\mathrm{p}=0.004)$ compared with colonoscopies in the morning. The trend analysis showed that there was a significant downward trend on CIR with the increasing procedure order $(\mathrm{OR}=0.76,95 \% \mathrm{CI}$ : $0.68-0.85$, $\mathrm{p}<0.001)$.
In subgroup analysis (Table V), the significant downward trend obtained from all colonoscopy data was also found in all subgroups except colonoscopies performed by endoscopists with age $\geq 40$ years old. In addition, significant higher CIR in the afternoon was only found in colonoscopies performed by endoscopists with male gender $(\mathrm{p}=0.004)$, age $<40$ years old $(\mathrm{p}<0.001)$ and high workload intensity $(\mathrm{p}=0.001)$.

Table V. Relationship between fatigue-related factors and cecal intubation rate stratified by different endoscopists ${ }^{`}$ factors

\begin{tabular}{|c|c|c|c|c|c|c|}
\hline & Male & Female & $<40$ years & $\geq 40$ years & $\begin{array}{c}\text { Intensity }(<50 \text { per } \\
\text { month })\end{array}$ & $\begin{array}{c}\text { Intensity ( } \geq 50 \text { per } \\
\text { month) }\end{array}$ \\
\hline \multicolumn{7}{|c|}{ Procedure order } \\
\hline $1-5$ & Reference & Reference & Reference & Reference & Reference & Reference \\
\hline $6-10$ & $0.77(0.63-0.94)$ & $0.64(0.52-0.79)$ & $0.62(0.52-0.74)$ & $0.89(0.69-1.14)$ & $0.74(0.61-0.89)$ & $0.62(0.49-0.79)$ \\
\hline$>10$ & $0.71(0.48-1.04)$ & $0.57(0.39-0.83)$ & $0.60(0.43-0.82)$ & $0.68(0.41-1.14)$ & $0.60(0.30-1.19)$ & $0.56(0.41-0.77)$ \\
\hline \multicolumn{7}{|c|}{ Session of procedure } \\
\hline Morning & Reference & Reference & Reference & Reference & Reference & Reference \\
\hline Afternoon & $1.34(1.10-1.62)$ & $1.17(0.96-1.43)$ & $1.47(1.22-1.77)$ & $0.94(0.75-1.17)$ & $1.08(0.92-1.28)$ & 1.55 (1.21-1.99) \\
\hline $\mathrm{p}$ for trend & 0.004 & 0.124 & $<0.001$ & 0.572 & 0.344 & 0.001 \\
\hline \multicolumn{7}{|l|}{ Day of week } \\
\hline Tuesday & $1.05(0.81-1.37)$ & $0.97(0.74-1.28)$ & $1.01(0.81-1.28)$ & $0.99(0.71-1.40)$ & $1.07(0.83-1.37)$ & $0.99(0.74-1.32)$ \\
\hline Wednesday & $1.20(0.93-1.54)$ & $1.26(0.93-1.71)$ & $1.15(0.91-1.47)$ & $1.46(1.03-2.07)$ & $1.19(0.93-1.54)$ & $1.23(0.89-1.69)$ \\
\hline Thursday & $1.26(0.98-1.62)$ & $0.92(0.69-1.24)$ & $1.05(0.83-1.34)$ & $1.16(0.82-1.63)$ & $1.15(0.89-1.49)$ & $1.08(0.80-1.45)$ \\
\hline Friday & $0.98(0.75-1.27)$ & $1.22(0.89-1.67)$ & $0.94(0.74-1.21)$ & $1.31(0.90-1.90)$ & $0.97(0.75-1.27)$ & $1.23(0.89-1.70)$ \\
\hline Weekends & $1.32(0.72-2.43)$ & $1.1(0.56-2.16)$ & $1.01(0.60-1.70)$ & $1.81(0.72-4.58)$ & $1.00(0.56-1.80)$ & $1.51(0.75-3.07)$ \\
\hline $\mathrm{p}$ for trend & 0.429 & 0.433 & 0.805 & 0.049 & 0.93 & 0.107 \\
\hline
\end{tabular}

Analyses were adjusted for fatigue, endoscopist and patient related factor when they were not the strata variables. Trend ${ }^{*}$, the variable was converted into ordinal variable and included into model. 


\section{DISCUSSION}

The workload of physicians has been a topic of debate for many years [7]. With the growing demand for colonoscopy in China, the endoscopist fatigue due to a high-intensity workload should be taken seriously [19]. In our research, a total of 34,022 colonoscopies performed by 21 endoscopists were included to explore whether the time or day when the colonoscopies were performed and whether the number of colonoscopy procedures would affect ADR and CIR.

The procedure order, also known as case rank or queue position, has been widely reported in the field of endoscopist fatigue in recent years. Most studies showed an absence of a major influence of case rank on $\operatorname{ADR}[14,16,17]$, which is consistent with our findings. However, we found a significant decrease in CIR as the procedure order rose in the multivariate regression analysis, indicating that an endoscopist' $s$ fatigue started to exist when performing 6 or more procedures per day.

The literature has explored the change of the colonoscopy quality with the timing of the operation [11-13,20]. Our results confirmed that the afternoon could cause a lower ADR compared to morning but had no significant influence on CIR. Some previous studies have shown an hour-by-hour progressive effect on the ADR decline [12,21], while a recent study in China demonstrated an inclined hourly trend in ADR [11]. To test these conclusions, we tried to draw the trend lines of ADR and CIR according to accurate timetable. Surprisingly, we found CIR declined gradually until 12 a.m., recovered at the beginning of afternoon, and then fell gradually to the lowest point again. Chances were high that an adequate lunch break could relieve fatigue and improve the quality of endoscopy by a lot. However, the expected downward trend did not show up in terms of ADR. One of the possible reasons for this reverse result is that our endoscopy center usually scheduled colonoscopies between 10:00-15:00 so that small samples examined before or after the regular time period distorted the result.

The day of the week is also a measure of fatigue worth being discussed. As far as we know, only one study conducted in a single endoscopy unit in Florida concentrated on the difference in ADR among the working days of the week [18]. Contrary to our conclusion, they found no statistically significant variation of ADR from Monday to Friday. However, they did not take endoscopist factors into consideration and the sample size was much smaller than ours with only 3,085 patients, which may account for the difference. In mixed effects regression models in our research, ADR dropped significantly on Fridays and weekends compared to Monday, and the progressive decline trend of ADR was obvious. A similar phenomenon was shown in the cytotechnologists that the abnormal detection rates and screening speed would decreased in the later days of a week [22]. The well-known 'weekend effect' demonstrated that an admission to a hospital at weekends would show a higher mortality than others probably because of the poor medical care partly caused by the fatigue of medical staff [23, 24]. Our study observed endoscopists' performance in weekends for the first time and found ADR in weekends dropped obviously compared to workdays, which was consistent with the 'weekend effect'. As our results suggested, endoscopists should not be encouraged to operate at the end of the week.
In order to investigate whether there were differences in tolerance of fatigue-related factors among endoscopists with different characteristics, we performed a logistic regression analysis using sex, age and workload intensity as bases for grouping. One of the most interesting findings was that male gender was more likely to explore progressive fatigue over the course of the week while females might be able to conquer this kind of fatigue. When grouped by the endoscopists' age, we found that endoscopists below 40 years old demonstrated a declined tendency of ADR and CIR respectively as the week progressed and as the daily procedures increased. Relatively, older doctors could perform stably in each day of a week, and they were qualified enough to examine over 10 cases in a single working day without obvious carelessness. Moreover, although the overall ADR and CIR of the endoscopists conducting over 50 colonoscopies per month was much better than others, only the endoscopists with a higher intensity showed a statistically significant ADR decline in later days of the week, which could reflect the negative effects of high workload to some extent. Adjusting the distribution of the daily workload by age and reducing the monthly procedures to a moderate number might be methods worth recommending. Another important fact is that all of the subgroups showed the afternoon led to a great decline in ADR, indicating that a prolonged and undisturbed lunch break or using 2 observers in the afternoon could be beneficial to all types of endoscopists.

In addition, we demonstrated a few other factors associated with ADR and CIR. Endoscopist's age, usually proportional to experience, was also shown to have a statistical impact on the colonoscopy quality. In terms of patient-related factors, advanced age, male gender, poor bowel preparation and operating without sedation could lead to a decline of ADR and CIR, as is demonstrated in many previous articles [25-27].

Our study still has a few limitations. Our study was retrospective research, which resulted in a lack of more convincing original data such as questionnaires or rating scales to assess physical and mental fatigue of endoscopists. Furthermore, we excluded senior endoscopists of our endoscopy center due to their unique working habits, which made our results limited to primary and intermediate endoscopists. Whether those senior doctors would be able to resist fatigue shown in our study remains to be seen.

To our knowledge, this is the first manuscript regarding the effect of weekends on screening colonoscopy.

\section{CONCLUSIONS}

This is a comprehensive study which has discussed whether fatigue would impact colonoscopy quality as assessed by ADR and CIR. Three surrogate markers of fatigue have been studied respectively in our research and the results we got were diverse. Colonoscopies performed in the afternoon will affect ADR negatively while the increasing procedure order will probably cause a significant lower CIR. The influence of an accurate timetable or adjusted intensity on colonoscopy quality still remains to be seen. A significant downward trend of ADR as the week progressed was shown in this research. In addition, we figured out that endoscopists with female gender and advanced 
age $(\geq 40)$ could show decided superiority in resistance of fatigue caused by the end of the week and the increasing daily procedures while those with high intensity ( $>50$ per month) could not maintain their good ADRs as a week progressed. Our study could be a basis for the working arrangement of endoscopy center in order to reduce fatigue-related mistakes and control the quality of colonoscopies.

\section{Conflicts of interest: None to declare.}

Authors' contributions: Z.D., J.W. and S.X. conceived the study. Z.D. and J.W. collected the data, analyzed the data and wrote this manuscript. Y.C., H.S. and B.L. collected the analyzed the data. Q.Z. K.S., Z.W., X.Q., T.Z., Y.J. collected the data and helped perform the analyses with constructive discussions. S.X. revised the manuscript.

Acknowledgements: The present study was supported by National Natural Science Foundation of China (grant nos. 81974067, 81600424 and 81570484), and Shanghai Shenkang Hospital Development Center (grant numbers SHDC12016109).

Supplementary material: To access the supplementary material visit the online version of the $J$ Gastrointestin Liver Dis at http://dx.doi. org/10.15403/jgld-3687.

\section{REFERENCES}

1. Ferlay J, Soerjomataram I, Dikshit R, et al. Cancer incidence and mortality worldwide: sources, methods and major patterns in GLOBOCAN 2012 Int J Cancer 2015;136:E359-E386. doi:10.1002/ijc.29210

2. Thirumurthi S, Ross WA. Adenoma Detection Rate as a Quality Metric: Is It Really Out of the Endoscopists' Hands? Dig Dis Sci 2019;64:33663368. doi:10.1007/s10620-019-05879-X

3. Zhao S, Wang S, Pan P, et al. Magnitude, Risk Factors, and Factors Associated With Adenoma Miss Rate of Tandem Colonoscopy: A Systematic Review and Meta-analysis. Gastroenterology 2019;156:16611674.e11. doi:10.1053/j.gastro.2019.01.260

4. Robertson DJ, Lieberman DA, Winawer SJ, et al. Colorectal cancers soon after colonoscopy: a pooled multicohort analysis. Gut 2014;63:949-956 doi:10.1136/gutjnl-2012-303796

5. Salam A, Segal DM, Abu-Helalah MA, et al. The impact of work-related stress on medication errors in Eastern Region Saudi Arabia. Int J Qual Health Care 2019;31:30-35. doi:10.1093/intqhc/mzy097

6. Westbrook JI, Raban MZ, Walter SR, Douglas H. Task errors by emergency physicians are associated with interruptions, multitasking, fatigue and working memory capacity: a prospective, direct observation study. BMJ Qual Saf 2018;27:655-663. doi:10.1136/bmjqs-2017-007333

7. Gates M, Wingert A, Featherstone R, Samuels C, Simon C, Dyson MP. Impact of fatigue and insufficient sleep on physician and patient outcomes: a systematic review. BMJ Open 2018;8:e21967. doi:10.1136/ bmjopen-2018-021967

8. Parker JB. The effects of fatigue on physician performance--an underestimated cause of physician impairment and increased patient risk. Can J Anaesth 1987;34:489-495. doi:10.1007/BF03014356

9. Gaba DM, Howard SK. Patient safety: fatigue among clinicians and the safety of patients. N Engl J Med 2002;347:1249-1255. doi:10.1056/ NEJMsa020846
10. Rex DK, Schoenfeld PS, Cohen J, et al. Quality indicators for colonoscopy. Gastrointest Endosc 2015;81:31-53. doi:10.1016/j. gie.2014.07.058

11. Xu Y, Chen K, Xu L, Yuan X, Wu Y, Chen P. Diagnostic yield is not influenced by the timing of screening endoscopy: morning versus afternoon. Scand J Gastroenterol 2018;53:365-369. doi:10.1080/0036 5521.2018 .1433230

12. Sanaka MR, Deepinder F, Thota PN, Lopez R, Burke CA. Adenomas are detected more often in morning than in afternoon colonoscopy. Am J Gastroenterol 2009;104:1659-1664. doi:10.1038/ajg.2009.249

13. Barakat M, Panchal A, Abdelfatah MM, Elhanafi S, Carr-Locke DL, Othman MO. Morning versus afternoon adenoma detection rate: a systematic review and meta-analysis. Eur J Gastroenterol Hepatol 2020;32:467-474. doi:10.1097/MEG.0000000000001596

14. Kang HY, Kim D, Kim HJ, et al. The Relationship Between Colonoscopy Procedure Order and Adenoma Detection Rates: A Prospective Study. J Clin Gastroenterol 2015;49:683-689. doi:10.1097/ MCG.0000000000000258

15. Paeck KH, Heo WJ, Park DI, et al. Colonoscopy scheduling influences adenoma and polyp detection rates. Hepatogastroenterology 2013;60:1647-1652.

16. Leffler DA, Kheraj R, Bhansali A, et al. Adenoma detection rates vary minimally with time of day and case rank: a prospective study of 2139 first screening colonoscopies. Gastrointest Endosc 2012;75:554-560. doi:10.1016/j.gie.2011.11.021

17. Lee A, Jensen CD, Marks AR, et al. Endoscopist fatigue estimates and colonoscopic adenoma detection in a large community-based setting. Gastrointest Endosc 2017;85:601-610.e2. doi:10.1016/j. gie.2016.09.033

18. Elsheikh TM, Kirkpatrick JL, Fischer D, Herbert KD, Renshaw AA Does the time of day or weekday affect screening accuracy? A pilot correlation study with cytotechnologist workload and abnormal rate detection using the ThinPrep Imaging System. Cancer Cytopathol 2010;118:41-46. doi:10.1002/cncy.20060

19. Harewood GC, Lieberman DA. Colonoscopy practice patterns since introduction of medicare coverage for average-risk screening Clin Gastroenterol Hepatol 2004;2:72-77. doi:10.1016/s15423565(03)00294-5

20. Subramanian S, Psarelli EE, Collins P, et al. Colonoscopy performance is stable during the course of an extended three-session working day Endosc Int Open 2015;3:E494-E500. doi:10.1055/s-0034-1392523

21. Singh S, Dhawan M, Chowdhry M, Babich M, Aoun E. Differences between morning and afternoon colonoscopies for adenoma detection in female and male patients. Ann Gastroenterol 2016;29:497-501. doi:10.20524/aog.2016.0079

22. Jimenez Cantisano BG, Hernandez M, Ramirez A, Castro FJ. The day of the week does not affect the adenoma detection rate. Dig Dis Sci 2014,59:564-568. doi:10.1007/s10620-013-2944-y

23. Bell CM, Redelmeier DA. Mortality among patients admitted to hospitals on weekends as compared with weekdays. N Engl J Med 2001;345:663-668. doi:10.1056/NEJMsa003376

24. Coiera E, Wang Y, Magrabi F, Concha OP, Gallego B, Runciman W Predicting the cumulative risk of death during hospitalization by modeling weekend, weekday and diurnal mortality risks. BMC Health Serv Res 2014;14:226. doi:10.1186/1472-6963-14-226

25. Lee TJ, Rees CJ, Blanks RG, et al. Colonoscopic factors associated with adenoma detection in a national colorectal cancer screening program. Endoscopy 2014;46:203-211. doi:10.1055/s-0033-1358831 
26. Maratt JK, Dickens J, Schoenfeld PS, et al. Factors Associated with Surveillance Adenoma and Sessile Serrated Polyp Detection Rates. Dig Dis Sci 2017;62:3579-3585. doi:10.1007/s10620-017-4792-7
27. Hsu CM, Lin WP, Su MY, Chiu CT, Ho YP, Chen PC. Factors that influence cecal intubation rate during colonoscopy in deeply sedated patients. J Gastroenterol Hepatol 2012,27:76-80. doi:10.1111/j.1440-1746.2011.06795.x 